University of Nebraska - Lincoln

DigitalCommons@University of Nebraska - Lincoln

Faculty Publications, Department of Psychology

Psychology, Department of

November 1992

\title{
Mutual Impacts of Toughening on Crises and Losses
}

Richard A. Dienstbier

University of Nebraska-Lincoln, rdienstbier2@unl.edu

Follow this and additional works at: https://digitalcommons.unl.edu/psychfacpub

Part of the Psychiatry and Psychology Commons

Dienstbier, Richard A., "Mutual Impacts of Toughening on Crises and Losses" (1992). Faculty Publications, Department of Psychology. 68.

https://digitalcommons.unl.edu/psychfacpub/68

This Article is brought to you for free and open access by the Psychology, Department of at DigitalCommons@University of Nebraska - Lincoln. It has been accepted for inclusion in Faculty Publications, Department of Psychology by an authorized administrator of DigitalCommons@University of Nebraska - Lincoln. 


\section{Mutual Impacts of Toughening on Crises and Losses}

Richard A. Dienstbier

University of Nebraska

It is usually expected that if we are overwhelmed by an episode of crisis or loss that we may temporarily cope ineffectively, whereas when we are exposed to a sequence of challenges and stressors that are managable, we learn gradually to become better able to cope with such events. The "toughness" concept relates to analogous processes at the physiological level. The concept is based upon a wide varicty of research with both animals and humans that is reviewed in detail elsewhere (Dienstbier, 1989). The focus of this chapter will instead be upon how toughness influences both physiological and psychological responses to life's crises and losses, and upon how those crises and losses in turn influence toughness.

The premise underlying toughness, is that while experience with overwhelming stressors will temporarily disrupt ideal physiological balances in the short term, regular exposure to challenges and stressors followed by adequate recovery periods can cause peripheral and central physiological changes that will increase one's future capacity for more positive forms of arousal and the suppression of more costly forms of arousal; resistance to depletion of some neuroendocrines will be enhanced. These relationships will be explicated more fully after a bricf section on definitions and an introduction to the elementary physiological concepts at issue.

My definitions of terms relevant to stress follow largely those of R.S. Lazarus. Following Lazarus and colleagues, both "challenge" and "stress" imply "a relationship between the person and the environment that is appraised by the person as relevant to his or her well-being and in which the person's resources are taxed or exceeded" (Folkman \& Lazarus, 1985, p. 152). "Challenge" is experienced when one anticipates success and the likelihood of the associated positive emotions; challenge holds the eventual potential for growth. "Stress" is divided into "loss," or injury already done, and "threat," understood as the potential for harm or loss. 
(Unlike Lazarus, I define "challenge" separately from "stress," including within my use of "stress" only the negative components of threat and harm/loss.) Finally, it is assumed that life crises may hold the potential for challenge as well as for stress.

Since modern research has shown most of the neural transmitters of interest here to have hormonal qualities, and the hormones to be used by some neurons as transmitters, the term "neuroendocrine" is used here to include both functions. Two neuroendocrine systems are central to this discussion:

The first peripheral arousal system, associated with the catecholamines (adrenaline, noradrenaline, and dopamine), emphasizes hypothalamic stimulation of the sympathetic nervous system (SNS) with associated release of noradrenaline, the transmitter of the SNS with hormonal action on nonneural tissue; SNS stimulation of the adrenal medulla causes the release of the neuroendocrine adrenaline. When the peripheral arousal function of this system is emphasized, it will be referred to as the "SNS-adrenal-medullary system." This peripheral arousal system is closely associated with the catecholamines of the central nervous system (CNS), of which noradrenaline and dopamine are of primary importance. Levels of central catecholamines often parallel peripheral catecholamine levels, though the mechanism for this correlation is not certain (Anisman \& LaPierre, 1982; Potter, Ross, \& Zavadil, 1985). For a number of reasons in this chapter I emphasize the positive adaptive character of episodic SNS-adrenal-medullary arousal in contexts of challenge/stress situations. As indicated below, such arousal stimulates desirable forms of energy at minimal physical and psychological cost, and it is capable of ending quickly when no longer required, as the peripheral catecholamines have a half-life of under 2 minutes in the human body.

The second arousal system depends upon hypothalamic stimulation of the pituitary, which releases adrenocorticotropin (ACTH). Carried by the circulatory system to the adrenal cortex, ACTH stimulates the release of cortisol, the adrenalcortical steroid of primary importance in humans. This system will be referred to as the "pituitary-adrenal-cortical system." I emphasize here the negative consequences of the pituitary-adrenal-cortical system. High levels of cortisol are associated with feelings of anxiety and depression, and result in suppression of the immune sytem. The half life of cortisol in the human body is around 90 minutes, so that when no longer needed, the quick reduction of pituitary-adrenal-cortical arousal to base-rate levels is not possible.

\section{THE TOUGHNESS PATTERN AND HOW ONE ACHIEVES IT}

The following paragraphs sketch only sections of research (reviewed thoroughly in Dienstbier, 1989) showing how toughening occurs, and once toughened, how the individual differs from those who are less fit. In summary, these studies show that in subsequent challenge/stress situations, the toughened individual will have an 
increased capacity to central catecholamine depletion. (This perspective is opposed to the common assumption that peripheral physiological arousal in all forms is usually harmful.) With increased peripheral and CNS catecholamine capacities, in those future challenge/stress contexts the more physiologically and psychologically costly pituitary-adrenal-cortical arousal is suppressed. Between episodes of challenge/stress, toughness is associated with generally lowered arousal base-rates.

Central Toughness: Animals that have been subjected to manipulations designed to induce behavioral suppression (or "learned helplessness," e.g., Weiss, Glazer, Pohorecky, Brick, \& Miller, 1975) and depressed humans (e.g., van Praag, 1986) show evidence of central catecholamine depletion. In the case of the behavioral suppression literature with animals, such depletions follow directly from short-term experience with stressors over which the animal had little or no control. On the other hand, daily handling or shocking throughout the early development of young animals (e.g., Meaney et al., 1987) or subjecting adult animals to a 14-day regime with stressors of the same type that cause short-term depletion of central catecholamines, or even inducing a 14-day central catecholamine depletion sequence with drugs (Glazer, Weiss, Pohorecky, \& Miller, 1975) results in long-term resistance to central catecholamine depletion and in resistance to behavioral suppression.

In summary, whether induced behaviorally or chemically, systematically exposing organisms to manipulations that cause central catecholamine depletion results in an increased ability of the organism to generate central catecholamines with resistance to central catecholamine depletion in the context of a future episode of challenge/stress.

Peripheral Toughness: Systematic aerobic training in humans (e.g., Hull, Young, \& Ziegler, 1984) and in animals (e.g., Brown \& Van Huss, 1973) causes an increase in the capacity of the organism to generate peripheral catecholamines when tested under maximum exercise conditions. That is, although training leads to increased physical efficiency, so that lower neuroendocrine levels are needed in the trained individual to achieve the same amount of work, training increases the capacity for more work and for more SNS-adrenal-medullary arousal. It will be shown later why this increased capacity is similarly important in response to psychological challenges and stresses. Fortunately, we have been able to show that following a 3-month period of aerobic training in college students, catecholamines generated in the context of psychological challenge/stress are increased compared to untrained controls and compared to themselves prior to training (Dienstbier, LaGuardia, Barnes, Tharp, \& Schmidt, 1987).

As individuals become tougher, with increased central and peripheral catecholamine capacity, they also become more sensitive to peripheral catecholamines; that is, a given amount infused into the body stimulates a greater arousal response; (this response is dependent upon the beta-receptors becoming 
more responsive to the catecholamines; Harri, 1979; Sklar \& Anisman, 1981). This increased sensivity is balanced by lower SNS-adrenal-medullary arousal base-rates during rest in the tough than in the unfit individual.

With increased catecholamine capacity, tough organisms show a reduced pituitary-adrenal-cortisol response in challenge/stress contexts. This reciprocal relationship between increased catecholamine capacity and reduced cortisol probably depends upon the inhibition of central ACTH generation being mediated by noradrenergic neurons in the CNS (Ganong, Kramer, Reid, Boryczka, \& Shackelford, 1976).

The various manipulations that have been shown to lead to some of the elements of toughening in adult animals include daily training with swimming in cold water, aerobic exercise, electric shock, and chemical depletion of catecholamines. Manipulations effectively used with young animals include daily handling, shocking, or living with adults of other species. Manipulations shown to be effective with humans include daily aerobic training and seasonal exposure to cold. ${ }^{1}$ For both animals (Ritter \& Pelzer, 1978) and humans (Faucheau, Bourlière, Baulon, \& Dupuis, 1981) aging leads to a physiological pattern that is like that of less fit organisms.

While some of these findings relate to central and some to peripheral catecholamine capacity increases in the tough, the distinction between central and peripheral arousal is blurred, for peripheral catecholamines often correspond with central catecholamine levels, and peripheral catecholamines have been shown to have a profound impact upon central functioning. For example, McGaugh (1983) has shown that in animals that have just completed a learning task, retention is facilitated when peripheral catecholamines are increased, while retention is severely reduced when peripheral catecholamine depletion occurs. A discussion of the means for such peripheral arousal influences on CNS functioning will be given below in the section on toughness and energy.

In summary of more research that has been reviewed here (but for more complete treatment, see Dienstbier, 1989), in contrast to less fit individuals, tough individuals show lower SNS-adrenal-medullary and lower pituitary-adrenal-cortical baserates of arousal, but in response to an episode of challenge or threat they show a faster and stronger SNS-adrenal-medullary arousal; pituitary-adrenal-cortical arousal is delayed. Following the challenge/stress situation, arousal declines faster in the tough than in the less fit. With loss or continuous threat, sufficient central catecholamine levels are maintained in the tough for longer periods than in the less fit (i.e., depletion is delayed), and again, cortisol arousal is delayed. Aging leads to

\footnotetext{
${ }^{1}$ The toughness concept is derived from a synthesis of research from many different research traditions with animals and humans. No single research project has attempted to show that any one manipulation leads to all of the physiological elements of toughness discussed here, nor has any single effort attempted to show a relationship between all of the physiological elements of toughness and the several personality, performance, and stress-tolerance dimensions discussed below.
} 
arousal patterns that are like those of the less fit, suggesting that as we age the behaviors that lead to toughening become increasingly important.

\section{IMPLICATIONS OF TOUGHNESS FOR PERSONALITY AND PERFORMANCE}

An analysis of the relevant research shows that certain activities or manipulations lead to a physiological syndrome (as described above) that in turn improves performance capabilities, personality (primarily emotional stability), and stress tolerance. (A discussion of how the physiological syndrome also impacts the immune and circulatory systems will be presented later.)

Two kinds of research derived from both animal and human subjects explicate these relationships. The first branch of research ignores the physiological mediators, showing that certain activities or manipulations that lead to toughening cause positive changes in the performance, personality, and stress tolerance variables. The second branch of research demonstrates relationships between elements of the physiological pattern of toughness and variables related to performance, personality, or stress tolerance.

\section{Manipulations Leading to Personality-Performance Changes}

In research with animals, the early-experience literature, cited briefly above, showed that even though such manipulations increased adrenal-gland weight (Levine, 1960) and catecholamine capacity (Pfeifer, 1976) those animals exposed to frequent stressors were more emotionally stable than controls. Similarly, the increased central catecholamine capacity shown in response to toughening manipulations in the 14-day programs of the research by Weiss and colleagues led to resistance to behavioral suppression or "helplessness." In research with humans, two decades of relatively weak research with regular aerobic exercise has shown the impact of such programs on increased emotional stability (for a review, see Dienstbier, 1984).

\section{Physiological Toughness Correlates with Personality and Performance}

Two research traditions with humans most closely addressed these issues: In the first, Frankenhaeuser and associated Scandinavian researchers have shown positive relationships between increases in catecholamines during mental challenge/ stress situations on the one hand and positive emotional adjustment on the other. (These relationships tend to be larger for adrenaline than for noradrenaline and larger for men than for women.) For example, children with higher adrenaline levels 
during an exam were rated by teachers as better adjusted, were more satisfied with school, and were more emotionally stable (Johansson, Frankenhaeuser, \& Magnusson, 1973). Older children with higher metriculation-exam catecholamine levels were similarly found to have lower psychosomatic symptomotology and, for boys, lower anxiety and higher achievement (Rauste-von Wright, von Wright, \& Frankenhaeuser, 1981). Catecholamine increases during exams were associated with higher MMPI measured ego strength in American male medical students (Roessler, Burch, \& Mefferd, 1967), and larger catecholamine increases during laboratory-induced stress situations were associated with lower neuroticism in Swedish male college students (Forsman, 1981).

Performance benefits are also associated with greater catecholamine (again stronger with adrenaline) increases during challenge/stress tasks. For example, the children in the Johansson et al. (1973) study whose catecholamines increased in the math test had fewer errors, particularly toward the end of that 45-minute test, than did the other children; similar relationships were found by Rauste-von Wright et al. (1981), particularly for boys (for a more extensive review, see Frankenhaeuser, 1979). Research by Ursin, Baade, and Levine (1978) with Norwegian paratrooper trainees measured catecholamine increases from before to after individual jumps from a training tower. Catecholamine increases correspond with higher performance in both written and jump-performance measures across an 11-day training period.

In summary, the research (sketched in the "Toughness Pattern" section, previously) shows that exposure to manipulations or activities consisting of regular sessions of either active (e.g., aerobic exercise programs) or passive (e.g., daily shocking or handling) activities that tax the central catecholamine capacities and/ or peripheral SNS-adrenal-medullary systems lead to the "tough" syndrome of physiological responses (detailed earlier). Research sketched in this section has shown first that those same activities are related to emotional stability, positive performance in challenge/stress situations, and resistance to behavioral suppression (and presumably resistance to depression as well) and the research has shown secondly that the mediating physiological syndrome is associated with that same pattern of emotional stability, positive performance, and so forth. The complete nomological net of relationships between these various elements is drawn in Dienstbier (1989).

\section{HOW TOUGHNESS RELATED TO ENERGY, PERFORMANCE, AND PERSONALITY}

Contrary to the often repeated speculations about the archaic nature of human emotional responses, high episodic arousal in response to mental challenge/stress situations is potentially beneficial. Although only a few percent of body weight, the brain is a major energy consumer, accounting for approximately $20 \%$ of our at-rest 
metabolism (Smith, 1970), with increases to over 25\% when challenging mental activities such as mental math are untertaken (Brod, 1970). Increased energy for mental activities is facilitated by peripheral as well as CNS arousal.

Both adrenaline and noradrenaline play a positive role in energy supply to the brain through circulatory system adjustments and through their role in the release and metabolism of glucose (where a primary role is played by adrenaline; Krotkiewski et al., 1983; Martin, 1985). Since glucose is the fuel of the nervous system and is directly influenced by adrenaline, the association between mental performance and adrenaline increases noted in the (largely) Scandinavian research is apparent.

On the other hand, noradrenaline increases correspond more highly with physical rather than mental activity (Frankenhaeuser, 1979). Noradrenaline is more involved than is adrenaline in the regulation of free fatty acids, and (with thyroxin) in regulating the conversion of fats to energy (Jansky, Mejsnar, \& Moravec, 1976). In combination with the SNS- and noradrenaline-mediated blood pressure increases, necessary for major muscle functioning, noradrenaline is ideally suited for increasing energy and efficiency when high levels of physical activity are required.

The relationship of toughness with the personality dimension of emotional stability is also apparent taking the foregoing into account. Consider the association of emotional instability (i.e., chronic anxiety or neuroticism) and depression on the one hand with high arousal base-rates, high cortisol levels (Anisman \& LaPierre, 1982; Persky, 1975), and lower SNS-adrenal-medullary response (Lader, 1983) on the other. The low arousal base-rates and delayed pituitary-adrenal-cortical responses and higher SNS-adrenal-medullary arousal (in challenge/stress situations) of the tough individual are physiological conditions associated therefore with emotional stability.

In addition to the impact of physiological toughness on performance and personality through the rather direct relationship of the tough neuroendocrine pattern leading both to mental and physical energy and to hormonal patterns associated with emotional stability, physiological toughness also apparently influences performance through its impact on appraisals or attributional processes. That influence is best understood by first considering the approach of Lazarus (1968) to coping.

\section{IMPLICATIONS FOR COPING WITH LIFE CRISES AND LOSSES}

In the Lazarus system, in the context of challenge or threat an individual makes a primary appraisal of the seriousness of the situation and its potential for positive or negative outcomes. That appraisal is followed by secondary appraisals of the skills and resources available for coping. The secondary appraisal in turn influences the primary appraisal, and so forth. My consideration of the importance of physiological toughness leads to a focus on energy levels as a principal resource that is taken 
into account in making secondary appraisals. That is, when coping will require a significant amount of energy (including situations in which only mental effort ist required), the physiological pattern of toughness will facilitate coping and, in an experienced individual, will be taken into account in making secondary appraisals. It is at this point that one of the fascinating relationships between mind and body becomes salient: When appraisals are made that success is likely (i.e., appraisals that the situation is a challenge more than a threat), the physiological pattern that results resembles, in the short term, the pattern described here as tough. Specifically, in the context of an appraisal of challenge, catecholamine levels increase while cortisol levels are held at base-rate levels or even reduced. Conversely, for an unfit individual with a history of low energy levels in the face of crises, the appraisals that are likely are that threat rather than challenge is imminent. With such an expectation, cortisol levels tend to increase along with catecholamine increases (Frankenhaeuser, Lundberg, \& Forsman, 1980).

Thus, appraisals of challenge or threat carry an element of self-fulfillment, not only at the psychological level, where different levels of effort and styles of coping are likely to follow, but more directly at a physiological level, with each inducing a different pattern of phyiological response-responses with challenge that are associated with energy without tension (see Figure 19.1) or with threat that are associated more with tension and anxiety than only energy (see Figure 19.2). For

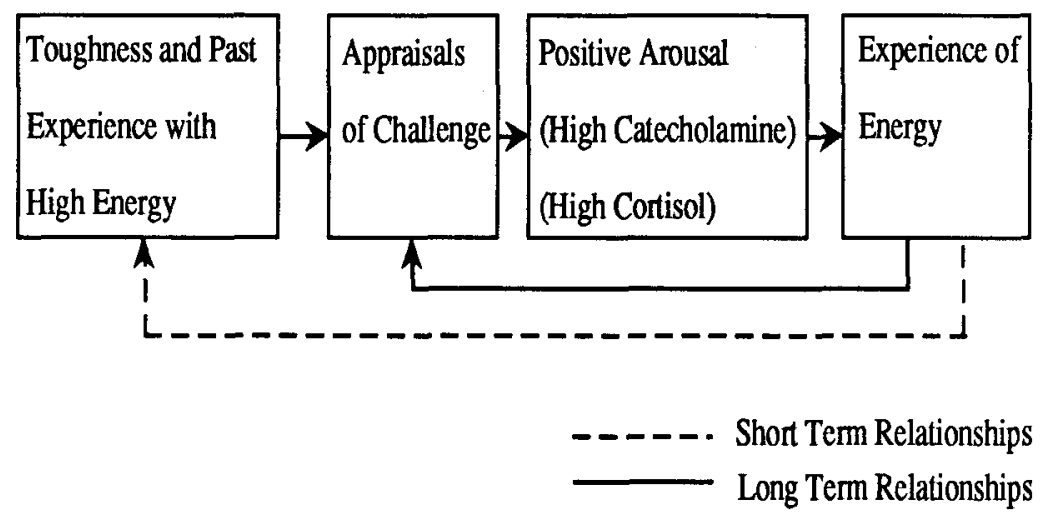

FIG. 19.1. Past experience being tough leads to appraisals of challenge, with a subsequent physiological arousal pattern that leads to energy and reinforcement of the expectation of success. 


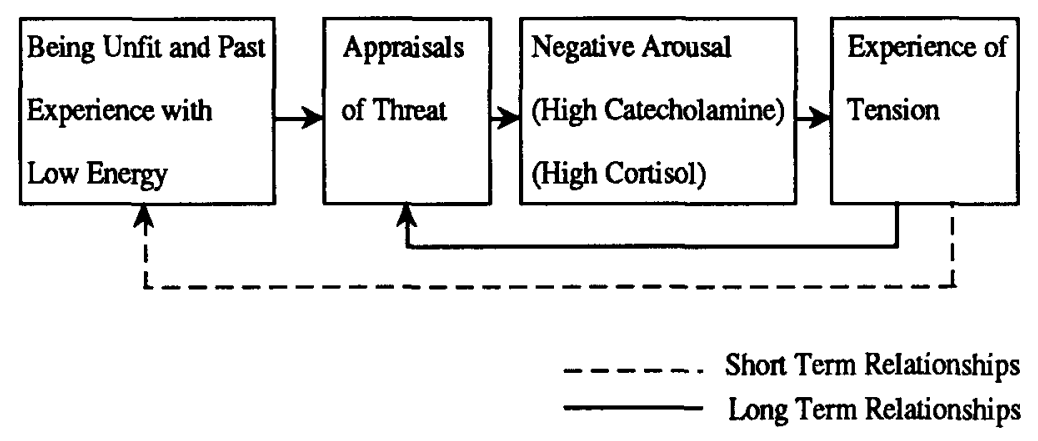

FIG. 19.2. Past experience of low energy in challenge/stress situations leads to appraisals of threat with a subsequent physiological arousal pattern that leads to tension and reinforcement of the expectation of failure.

reviews of the remarkable research underlying these observations, see Frankenhaeuser (1982) and Forsman (1983).

In the long term, expectations of success from challenge/threat situations are likely to lead to one seeking out stimulating situations. Regular experience with such stimulating situations is likely to lead, in turn, to toughening, increasing the potential for success in future situations, and leading to more adventurousness, etc. These relationships between appraisals and physiological responses in the short and long terms are shown in Figure 19.3, as are some relationships between toughness and immune processes to be discussed below.

Situations involving loss are almost by definition situations that are aversive without permitting effective instrumental activities. Such situations tend to lead to brain catecholamine depletion (in animal research such as that of Weiss \& Glazer, 1975) and to high cortisol secretion levels (as shown by human research such as that of Rodin, 1980).

The research by Weiss and colleagues on behavioral suppression, reviewed above, clearly shows direct physiological benefits from toughness. In the context of even inescapable stressors, tougher individuals sustain less depletion of central catecholamines (Weiss et al., 1975) and delayed pituitary-adrenal-cortical responses (Starzec, Berger, \& Hesse, 1983). Since CNS catecholamine exhaustion and high cortisol levels are both associated with depression and since cortisol levels are associated with suppression of the immune system, toughness is likely to result in delay of onset and perhaps avoidance of the problems of both mental and physical health that are associated with severe loss experiences.

In loss situations as in crises, the tough individual may gain advantages through the modified attributions that are likely to follow from a history of energy in difficult situations and from reduced depression. If a history of success leads to even a mistaken belief that one has control, then the pattern of physiological arousal will tend more to resemble that associated with toughness. 


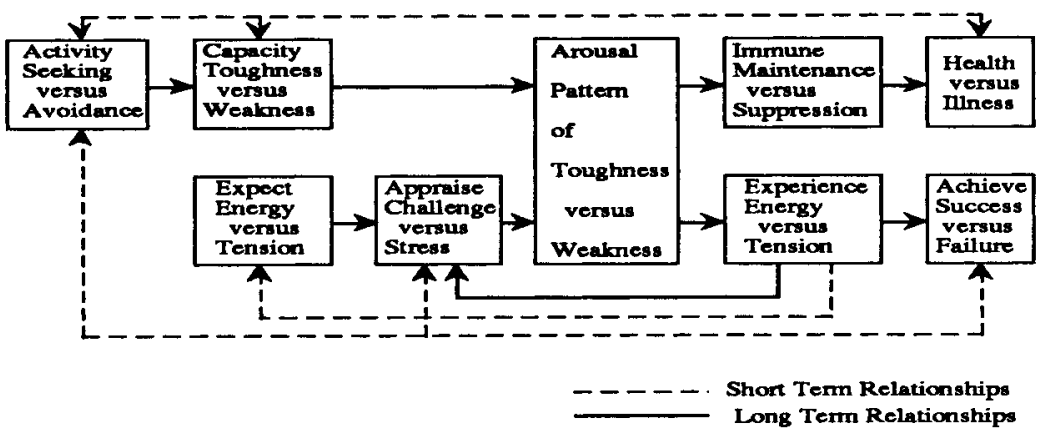

FIG. 19.3. Interrelationships between toughness (versus weakness) and the behavioral, psychological and physiological concomitants.

\section{HOW TOUGHNESS RELATES TO HEALTH}

\section{Toughness and the Immune System}

Most acute laboratory stressors used with animals, including shock, cold, or social stressors such as crowding, suppress immune functioning and cause susceptibility to all phases of tumor growth (Calabrese, Kling, \& Gold, 1987; Sklar \& Anisman, 1981). Long-term "crises" for humans such as living near the site of a nuclear power plant accident (Three Mile Island) and losses such as bereavement or being assigned to a nursing home similarly increase morbidity and mortality (Baum, 1986; Rodin, 1980).

Apparently the most damaging aspect to the immune system of the physiological response to stressful situations is the suppression of immune function by cortisol. Since toughness is associated with delayed cortisol responses, toughening should result in less disease when individuals experience crises or loss. Research with animals strongly supports this prediction. Sklar and Anisman (1981) noted that regular exposure to most laboratory stressors (from shock to cold, but not to social stressors) results in enhanced immune function and resistance to all phases of cancerous growth. Such positive effects from chronic stress are enhanced if the stress occurs before or soon after exposure to experimentally induced pathogens and if the animals have some control (Solomon, Kay, \& Morley, 1986) over the stressors. $^{2}$

${ }^{2}$ Cortisol suppresses immune system functioning by inhibiting the secretion of lymphokines (including interferons and interlukins) and depressing helper T-cell functioning. However, central and peripheral catecholamine availability enhances natural killer cell activity. Exposure to toughening manipulations leads to inhanced interferon production (Calabrese, Kling, \& Gold, 1987; Sklar \& Anisman, 1981; Solomon, Kay, \& Morley, 1986). 
These data support the frequently heard informal observation of individuals enjoying recently acquired exercise habits that their disease resistance is thereby strengthened, and suggest that a history of toughening activities before crises or loss will be prophylactic for both mental and physical health.

\section{Toughness, Crises, and Cardiovascular Health}

My analysis of the role played by toughness in the maintenance of cardiovascular health during crises or loss is based largely upon the literature on Type A personality.

Once it was noted that there is a connection between Type A personality disposition (time-concern, competitiveness, and hostility, labelled "Type A") and various cardiovascular diseases (hereafter coronary heart disease or $\mathrm{CHD}$ ), researchers began to search for the expected mediating physiological variables (Matthews et al., 1986; Williams, 1986). Recent research indicates that higher peripheral physiological arousal or greater cardiovascular and neuroendocrine "responsivity" is often found for Type A's, especially in circumstances of difficult or challenging tasks (Holmes, McGilley, \& Houston, 1984), previous "warmups" in other stimulating tasks (Ortega \& Pipal, 1984), very competitive situations (Chesney \& Rosenman, 1983), or understimulation (Lundberg, 1983).

Since toughness is associated with increased SNS-adrenal-medullary responsivity, toughness and the response characteristics of Type A persons look superficially similar, suggesting enhanced risks from toughness, particularly with frequent experiences of crises or losses. A superficial look at the literature appears to support this bleak conclusion, for there is a large and growing literature on the association of CHD with cardiovascular and autonomic reactivity to stressors (e.g., Matthews et al., 1986). For example, autonomically responsive animals show atherosclerosis of coronary arteries, elevated blood pressure, and similar unhealthy states (e.g., Manuck \& Krantz, 1986). However, while most of the studies in this area define cardiovascular responsivity by base-rate to stressor-condition increases, few provide information about catecholamine or cortisol levels, and few provide data on speed of recovery from arousal (Matthews, 1986).

The recovery information is a crucial, since the tough recover quickly from SNS-adrenal-medullary arousal. Fortunately for the tough, reviews of studies of monkeys (e.g., Clarkson, Manuck, \& Kaplan, 1986), and humans (e.g., Goldstein \& McDonald, 1986; Ursin, 1978) have similarly concluded that it is the total duration of heightened arousal over long time periods (months or years) that leads to $\mathrm{CHD}$. Other research has shown that unlike tough individuals, Type A persons recover more slowly from SNS-adrenal-medullary arousal, as demonstrated by slower T-wave response recovery in Type A's than B's following infusion of noradrenaline (Williams, 1986). 
Additional differences between Type A's and the tough relate to arousal baserates. That is, arousal base-rates on several parameters are higher in Type A's; those same arousal characteristics are associated with neuroticism and hostility-personality characteristics often associated with Type A's. On the other hand those arousal base-rates tend to be lower in the tough, especially as measured by urinary catecholamines (Forsman, 1981). In the context of challenges or crises, cortisol levels are higher for Type A's in contrast to others, while delayed cortisol secretion is a characteristic of toughness. For example, in studies of neuroendocrine responses to mental math, Williams (1986) noted that while Type A's gave higher adrenaline and noradrenaline responses, even greater differences in cortisol levels developed between Types A and B (with A's higher). Williams suggested that testosterone and cortisol hyper-responsivity were probably the major factors in CHD risk. Ursin and Knardahl(1985) reached similar conclusions, noting that Type A's with family histories of CHD had higher cortisol levels than other Type A's. Finally, in a review of neuroendocrine mechanisms in CHD, Herd (1986) cited more experimental evidence for the involvement of cortisol than for the catecholamines in fostering the vascular conditions leading to heart disease.

In conclusion, although "hyperresponsive" Type A's are prone to $\mathrm{CHD}$, and although at first glance the tough seem similar, with their increased SNS-adrenalmedullary responsivity in challenge/stress situations, Type A's and the tough differ on the physiological and personality dimensions that seem crucial. That is, in contrast to Type A's (and to a lesser extent in contrast to the less fit) the tough have lower arousal base-rates and lower cortisol responsivity with quicker recovery from arousal. While Type $A$ is associated with neuroticism, associated with lower rather than higher SNS-adrenal-medullary responses to challenge/stress albeit higher SNS base-rates (Lader, 1983), and with higher cortisol responsivity (Persky, 1975), toughness is associated with emotional stability.

These observations would suggest that in times of crisis and loss, when health risks are potentially increased by high arousal base-rates and by pituitary-adrenalcortical arousal, that toughness is prophylactic rather than a risk factor in CHD.

\section{RESEARCH ON LIFE EVENTS FROM THE PERSPECTIVE OF TOUGHNESS}

The crises and losses that are the topic of this volume are usually major negative life events, and so they will usually be associated with health problems, as suggested by the foregoing section. However, like challenge/threat situations generally, in addition to causing short-term health problems, in the long term some life events may have the potential to toughen.

Researchers in the "life events" area originally endeavored to show that major negative or positive changes in life requiring "restructuring" result in increased incidences of illness (Holmes \& Rahe, 1967). Indeed, they were initially quite 
successful as reflected in the association of life changes or "events" with illness being accepted in most introductory psychology texts. But research reviewed above suggests that regular or frequent exposure to positive life events (often experienced as challenges) and even frequent exposure to stressors that evoke SNS-adrenalmedullary arousal should lead to toughness, eventually impacting immunological function positively, and causing no CHD problems (e.g., Sklar \& Anisman, 1981). How are these differences to be resolved?

The life-events field has been characterized by an increasing proportion of articles focusing upon methodological problems (Kasl, 1983). Early critiques of retrospective studies emphasized the problems of defining causal direction (e.g., would current illnesses bias recall of life events). Current critiques of the more recent prospective studies and of more objectively anchored retrospective studies still emphasize causal problems. For example, Kasl noted that third factors are frequently ignored (e.g., while certain medical specialities characterized by higher stress also show higher CHD, the physicians in those fields smoke more; young people sustain many more life events and have more illnesses than older individuals, so that the life events to illness correlation may be due to age as a third factor). Finally, many life events (e.g., divorce, job loss) may develop over long time periods and may be influenced by health rather than the reverse.

In Kasl's analysis, to eliminate such problems, one must eliminate from the lifeevents inventories those events that are possibly influenced by health and those that are under the individual's control (i.e., related to life style). With the 43-item Holmes and Rahe (1967) scale, one is then left with death of spouse, close family member. Schroeder and Costa (1984) argue that when the vague life-events items are eliminated, results do not support a general "life events to illness" hypothesis, and that prospective studies using objective measures of illness fail to show the predicted effects.

By itself, Kasl's (1983) thorough critique is devastating for most life-events research. Other critics have approached the methodological problems from different perspectives, with similar impact. For example, although both positive and negative life events are included in most scales (such as the Holmes and Rahe scale, 1967), those studies that have compared their impacts generally find nocorrelations between positive events and illness (see the review by Thoits, 1983). For example, in Theorell's (1976) large-scale prospective study of almost 10.000 building construction workers, only life events causing "discord" were found to be related to later illness incidences. In their review of depression, Anisman and LaPierre (1982) noted that only undesirable or unpleasant life events (rather than change per se) are associated with depression. Rabkin and Struening (1976) go further by suggesting that a relationship between life events and illness is evident only when positive life events are substracted from negative ones.

In summary, the toughening concept predicts no negative impacts from life events other than those life crises and losses that cause high levels of distress (and that therefore deplete catecholamines and/or increase cortisol). Toughness, whether 
through genetic predisposition or through experience with regular challenge/stress situations, should attenuate those negative impacts from crises and losses. In fact, this model predicts health benefits from frequent exposure to positive life events, particularly those associated with a feeling of control. In studying job environments, Karasek, Russell, and Theorell (1982) have identified challenging occupations with high control as leading to some of the same physiological changes associated with toughness.

\section{WHAT EXPERIENCES LEAD TO TOUGHENING?}

Apparently tough individuals are able to face crises and losses with less negative impact on their mental and physical health than are the less fit. At issue in this section is the question of what kinds of experiences or perceptions of experience may have the most positive impact on the development of physiological toughness.

Research reviewed above has shown that regular stress such as electric shock and regular exercise effectively stimulate the development of toughness in laboratory animals. Exposure to cold and aerobic exercise have been shown to lead to similar results in humans. I have suggested elsewhere that the association of the humor response with catecholamine generation (Fry, 1986) in individuals who are bed-ridden suggests that humor may toughen, and research by Karasek et al. (1982) suggests in a preliminary way that occupational challenge (with control) may lead to toughening. I would speculatively add to this list that positive forms of social interaction that are high in stimulation quality may serve similar functions.

In the abstract, the toughening of any physiological system seems dependent upon a rhythm of regular stimulation followed by an interval during which recovery (eventually beyond initial levels of capability) is possible. I suspect that the reason that social stressors such as crowding are not effective (in laboratory animals; Sklar \& Anisman, 1981) is that the necessary recovery intervals are missing.

In human life, if our "crises" are daily events (e.g., demanding deadlines as in editing a newspaper), they should toughen us unless we are unable to stop worrying once each "crisis" has been met. Major losses, on the other hand, are likely to be infrequent and to elicit pituitary-adrenal-cortical responses as much or more than SNS-adrenal-medullary responses. If they preoccupy us for long periods, such as is often the case with deaths, they are likely to provide insufficient recovery periods for toughness to develop and to cause depletion of catecholamines, rather than increased neuroendocrine resources.

In conclusion, it has been popular to say that we need some "stress" in our lives to remain appropriately stimulated and to grow. Terms such as Selye's (1956) "eustress" have been coined to suggest this positive aspect of stress. In my terms, as defined in this chapter, we will certainly benefit by becoming tougher through regular exposure to challenges that are physical, and probably as well through 
exposure to those that are mental; we will probably benefit through periodic exposure to some milder life crises-situations that may threaten us, provided we have recovery periods, probably at nearly daily intervals (precluding extensive worrying). On the other hand, while we will face any challenge, threat, or harm/loss situation with more energy and with higher neuroendocrine reserves if we are tough, we should not expect to toughen from severe harm/losses.

\section{REFERENCES}

Anisman, H., \& LaPierre, Y. (1982). Neurochemical aspects of stress and depression: Formulations and caveats. In R.W. Neufeld (Ed.), Psychological stress and psychopathology (pp. 179-217). New York: MoGraw-Hill.

Baum, A. S. (1986, August). Chronic and extreme stress: Psychobiological influences on health. Paper presented at the annual meeting of the American Psychological Association, Washington, DC.

Brod, J. (1970). Haemodynamics of emotional stress. In M. Koster, H. Musaph, \& P. Viser (Eds.), Psychosomatics in essential hypertension (pp. 13-37). Basel: Karger.

Brown, B. S., \& Van Huss, W. (1973). Exercise and rat brain catecholamines. Journal of Applied Physiology, 34, 664-669.

Calabrese, J. R., Kling, M. A., \& Gold, P. W. (1987). Alterations in immunocompetence during stress, bereavement, and depression: Focus on neuroendocrine regulation. American Journal of Psychiatry, $144,1123-1134$.

Chesney, M. A., \& Rosenman, R. H. (1983). Specificity in stress models: Examples drawn from Type A behavior. In C. L. Cooper (Ed.), Stress research: Issues for the eighties (pp. 21-34). New York: Wiley.

Clarkson, T. B., Manuck, S. B., \& Kaplan, J. R. (1986). Potential role of cardiovascular reactivity in atherogenesis. In K. A. Matthews, S. M. Weiss, T. Detre, T. M. Dembroski, B. Falkner, S. B. Manuck, \& R. B. Williams, Jr. (Eds.), Handbook of stress, reactivity, and cardiovascular disease (pp. 35-48). New York: Wiley.

Dienstbier, R. A. (1984). The effect of exercise on personality. In M. L. Sachs \& G. B. Buffone (Eds.), Running as therapy: An integrated approach (pp. 253-272). Lincoln: University of Nebraska Press.

Dienstbier, R. A. (1989). Arousal and physiological toughness: Implications for mental and physical health. Psychological Review, 96, 84-100.

Dienstbier, R. A., LaGuardia, R. L., Barnes, M., Tharp, G., \& Schmidt, R. (1987). Catecholamine training effects from exercise programs: A bridge to exercise-temperament relationships. Motivation and Emotion, 11, 297-318.

Faucheau, B. A., Bourlière, F., Baulon, A., \& Dupuis, C. (1981). The effects of psychosocial stress on urinary excretion of adrenaline and noradrenaline in 51- to 55- and 71- to 74-year-old men. Gerontology, 27, 313-325.

Folkman, S., \& Lazarus, R. S. (1985). If it changes it must be a process: Study of emotion and coping during three stages of a college examination. Journal of Personality and Social Psychology, 48, 150170.

Forsman, L. (1981). Habitual catecholamine excretion and its relation to habitual distress. Biological Psychology, 11, 83-97.

Forsman, L. (1983). Individual and group differences in psychophysiological responses to stress-With emphasis on sympathet ic-adrenal medullary and pituitary-adrenal corticol responses. Unpublished doctoral dissertation, University of Stockholm, Sweden.

Frankenhaeuser, M. (1979). Psychoneuroendocrine approaches to the study of emotion as related to stress and coping. In H. E. Howe, Jr., \& R. A. Dienstbier(Eds.), Nebraska Sympasium on Motivation, 1978: Human emotion (Vol. 27, pp. 123-161). Lincoln: University of Nebraska Press. 
Frankenhaeuser, M. (1982). Challenge-control interaction as reflected in sympathetic-adrenal and pituitary-adrenal activity: Comparison between the sexes. Scandinavian Journal of Psychology, (Suppl. 1), 158-164.

Frankenhaeuser, M., Lundberg, U., \& Forsman, L. (1980). Dissociation between sympathetic-adrenal and pituitary-adrenal responses to an achievement situation characterized by high controllability: Comparison between Type A and Type B males and females. Biological Psychology, 10, 79-91.

Fry, W. R., Jr. (1986). Humor, physiology, and the aging process. In L. Nahemow, K. A. McCluskeyFawcett, \& P. E. McGhee (Eds.), Humor and aging (pp. 91-98). Ortando, FL: Academic Press.

Ganong, W. F., Kramer, N., Reid, I. A., Boryczka, A. T., \& Shackelfond, R. (1976). Inhibition of stressinduced ACTH secretion by norepinephrine in the dog: Mechanism and site of action. In E. Usdin, R. Kvetnansky, \& I. J. Kopin (Eds.), Catecholamines and stress (pp. 139-144). Oxford, England: Pergamon.

Glazer, H. I., Weiss, J. M., Pohorecky, L. A., \& Miller, N. E. (1975). Monoamines as mediators of avoidance-escape behavior. Psychosomatic Medicine, 37, 535-543.

Goldstein, D. S., \& McDonald, R. H. (1986). Biochemical indices of cardiovascular reactivity. In K. A. Matthews, S. M. Weiss, T. Detre, T. M. Dembroski, B. Falkner, S. B. Manuck, \& R. B. Williams, Jr. (Eds.), Handbook of stress, reactivity, and cardiovascular disease (pp. 187-203). New York: Wiley.

Harri, M. N. E. (1979). Physical training under the influence of beta-blockade in rats. II: Effects on vascular reactivity. European Journal of Applied Physiology, 42, 151-157.

Herd, J. A. (1986). Neuroendocrine mechanisms in coronary heart disease. In K. A. Matthews, S. M. Weiss, T. Detre, T. M. Dembroski, B. Falkner, S. B. Manuck, \& R. B. Williams, Jr. (Eds.), Handbook of stress, reactivity, and cardiovascular disease (pp. 49-70). New York: Wiley.

Holmes, D. S., McGilley, B. M., \& Houston, B. K. (1984). Task-related arousal of Type A and Type B persons: Level of challenge and response specifity. Journal of Personality and Social Psychology, $46,1322-1327$.

Holmes, T. H., \& Rahe, R. H. (1967). The Social Readjustment Rating Scale. Journal of Psychosomatic Research, 11, 213-218.

Hull, E., Young, S., \& Ziegler, M. (1984). Aerobic fitness affects cardiovascular and catecholamine responses to stressors. Psychophysiology, 21, 253-260.

Jansky, L., Mejsnar, J., \& Moravec, J. (1976). Catecholamines and cold stress. In E. Usdin, R. Kvetnansky, \& I. J. Kopin (Eds.), Catecholamines and stress (pp. 419-434). Oxford, England: Pergamon.

Johansson, G., Frankenhaeuser, M., \& Magnusson, D. (1973). Catecholamine output in school children as related to performance and adjustment. Scandinavian Journal of Psychology, 14, 20-28.

Karasek, R. A., Russell, R. S., \& Theorell, T. (1982). Physiology of stress and regeneration in job-related cardiovascular illness. Journal of Human Stress, 8(1), 29-42.

Kasl, S. V. (1983). Pursuing the link between stressful life experiences and disease: A time for reappraisal. In C. L. Cooper (Ed.), Stress research: Issues for the eighties (pp. 79-102). New York: Wiley.

Krotkiewski, M., Mandroukas, K., Morgan, L., William-Olsson, T., Feurle, G. E., von Schenck, H., Bjomtorp, P., Sjostrom, L., \& Smith, U. (1983). Effects of physical training on adrenergic sensitivity in obesity. Journal of Applied Physiology, 55, 1811-1817.

Lader, M. (1983). Anxiety and depression. In A. Gale \& J. A. Edwards (Eds.), Physiological correlates of human behavior. Vol. III: Individual differences and psychopathology (pp. 155-167). London: Academic Press.

Lazanus, R. S. (1968). Emotions and adaptation: Conceptual and empirical relations. In W. J. Amold (Ed.), Nebraska Symposium on Motivation (Vol. 16, pp. 175-266). Lincoln: University of Nebraska Press.

Levine, S. (1960). Stimulation in infancy. Scientific American, 202, 80-86.

Lundberg, U. (1983). Psychoneuroendocrine aspects of mental work as related to Type A behaviour. In H. Ursin \& R. Murison (Eds.), Biological and psychological basis of psychosomatic disease (pp. 193 207). Oxford: Pergamon. 
Manuck, S. B., \& Krantz, D. S. (1986). Psychophysiologic reactivity in coronary heart disease and essential hypertension. In K. A. Mathews, S. M. Weiss, T. Detre, T. M. Dembroski, B. Falkner, S. D. Manuck, \& R. B. Williams, Jr. (Eds.), Handbook of stress, reactivity, and cardiovascular disease (pp. 11-34). New York: Wiley.

Martin, C. R. (1985). Endocrine physiology. New York: Oxford University Press.

Matthews, K. A. (1986). Summary, conclusions, and implications. In K. A. Matthews, S. M. Weiss, T. Detre, T. M. Dembroski, B. Falkner, S. B. Manuck, \& R. B. Williams, Jr. (Eds.), Handbook of stress, reactivity, and cardiovascular disease (pp. 461-473). New York: Wiley.

Matthews, K. A., Weiss, S. M., Detre, T., Dembroski, T. M., Falkner, B., Manuck, S. B., \& Williams, R. B., Jr. (Eds.). (1986). Handbook of stress, reactivity, and cardiovascular disease. New York: Wiley.

McGaugh, J. L. (1983). Preserving the presence of the past: Hormonal influences on memory storage. American Psychologist, 38, 161-174.

Meaney, M. J., Aitkens, D. H., Berkel, C., Bhatnagar, S., Sarrieau, A., \& Sapolsky, R. M. (1987). Postnatal handling attenuates age-related changes in the adrenocortical stress response and spatial memory deficits in the rat. Paperpresented at the 17 th Annual Meeting of the Society of Neuroscience, New Orleans.

Ortega, D. F., \& Pipal, J. E. (1984). Challenge seeking and the Type A coronary-prone behavior pattem. Journal of Personality and Social Psychology, 46, 1328-1334.

Persky, H. (1975). Adrenocortical function and anxiety. Psychoneuroendocrinology, 1, 37-44.

Pfeifer, W. D. (1976). Modification of adrenal tyrosine hydroxylase activity in rats following manipulation in infancy. In E. Usdin, R. Kvetnansky, \& I. J. Kopin (Eds.), Catecholamines and stress (pp. 265-270). Oxford, England: Pergamon.

Potter, W.Z., Ross, R. J., \& Zavadil, A. P., III (1985). Nonepinephrine in the affective disorders: Classic biochemical approaches. In C. R. Lake \& M. G. Ziegler (Eds.), The catecholamines in psychiatric and newrologic disorders (pp. 213-233). Boston: Butterworth.

Rabkin, J. G., \& Struening, E.L. (1976). Life events, stress, and illness. Science, 194, 1013-1020.

Rauste-von Wright, M., von Wright, J., \& Frankenhaeuser, M. (1981). Relationships between sexrelated psychological characteristics during adolescence and catecholamine excretion during achievement stress. Psychophysiology, 18, 362-370.

Ritter,S., \& Pelzer, N. L. (1978). Magnitude of stress-induced brain norepinephrine depletion varies with age. Brain Research, 152, 170-175.

Rodin, J. (1980). Managing the stress of aging: The role of control and coping. In S. Levine \& H. Ursin (Eds.), Coping and health (pp. 171-202). New York: Plenum.

Roessler, R., Burch, N. R., \& Mefferd, R. B. (1967). Personality correlates of catecholamine excretion under stress. Journal of Psychosomatic Research, 11, 181-185.

Schroeder, D. H., \& Costa, P. T., Jr. (1984). Influence of life event stress on physical illness: Substantive effects or methodological flaws? Journal of Personality and Social Psychology, 46, 853-863.

Selye, H. (1956). The stress of life. New York: McGraw-Hill.

Sklar, L. S., \& Anisman, H. (1981). Stress and cancer. Psychological Bulletin, 89, 369-406.

Smith, C. U. M. (1970). The brain. New York: Putnam.

Solomon, G. S., Kay, N., \& Morley, J. E. (1986). Endorphins: A link between personality, stress, emotions, immunity, and disease? In N. P. Plotnikoff, R. E. Faith, A. J. Murgo, \& R. A. Good (Eds.), Enkephalins and endorphins: Stress and the immune system (pp. 129-144). New York: Plenum.

Starzec, J. J., Berger, D. F., \& Hesse, R. (1983). Effects of stress and exercise on plasma corticosterone, plasma cholesterol, and aortic cholesterol levels in rats. Psychosomatic Medicine, 45, 219-226.

Theorell, T. (1976). Selected illnesses and somatic factors in relation to two psychosocial stress indices: A prospective study on middle-aged constnuction building workers. Journal of Psychosomatic Research, 20, 7-20.

Thoits, P. A. (1983). Dimensions of life events that influence psychological distress: An evaluation and synthesis of the literature. In H. B. Kaplan (Ed.), Psychasocial stress: Trends in theory and research (pp. 33-103). New York: Academic Press.

Ursin, H. (1978). Activation, coping, and psychosomatics. In H. Ursin, E. Baade, \& S. Levine (Eds.), Psychobiology of stress: A study of coping men (pp. 201-228). New York: Academic Press. 


\section{DIENSTBIER}

Ursin, H., Baade, E., \& Levine, S. (Eds.). (1978). Psychobiology of stress: A study of coping men. New York: Academic Press.

Ursin, H., \& Knardahl, S. (1985). Personality factors, neuroendocrine response patterns, and cardiovascular pathology. In J. F. Orlebeke, G. Mulder, \& L. J. P. van Doomen (Eds.), The psychophysiology of cardiovascular control (pp. 715-731). New York: Plenum.

van Praag, H. M. (1986). Monoamines and depression: The present state of the art. In R. Plutchik \& H. Kellerman (Eds.), Emotion: Theory, research, and experience. Vol. 3: Biological foundations of emotion (pp. 335-361). Orlando, FL: Academic Press.

Weiss, J. M., \& Glazer, H. I. (1975). Effects of acute exposure to stressors on subsequent avoidanceescape behavior. Psychosomatic Medicine, 37, 499-521.

Weiss, J. M., Glazer, H. I., Pohorecky, L. A., Brick, J., \& Miller, N. E. (1975). Effects of chronic exposure to stressors on avoidance-escape behavior and on brain norepinephrine. Psychosomatic Medicine, 37, 522-534.

Williams, R. B., Jr. (1986, August). Beyond Type A:Psychological and physiological refinements. Paper presented at the meeting of the American Psychological Association, Washington, DC. 